\title{
COMPARING THE INVOLVEMENT OF ACADEMIC LIBRARIANS IN THE CYCLICAL REVIEW PROCESS FOR GRADUATE PROGRAMS IN THE HUMANITIES AND IN THE SCIENCES
}

\begin{abstract}
:
In Ontario, all graduate programs at publicly assisted universities must be reviewed on a cyclical basis at least once every eight years. This paper adopts a corpus-based approach to investigate and compare how academic librarians are integrated into the cyclical review process for graduate programs in the Humanities and graduate programs in the Sciences. Findings reveal that these two broad disciplinary cultures differ in the way and the degree to which they recognize libraries and involve librarians in the program review process.
\end{abstract}

\section{Introduction}

In Ontario, quality assurance of academic programs has gained prominence in recent years (e.g. Goff 2013; Liu 2015). Programs at publicly assisted universities must be reviewed at least once every eight years, and there is a focus on continuous improvement and on ensuring that students meet program objectives. Yet while the emphasis on program enhancement is on the rise, it is not clear whether and/or how librarians are involved in these reviews in a meaningful way. Nicholson et al. (2011) and Jackson (2017), for instance, have observed that the types of questions asked during review processes still tend to focus on the "traditional" view of the library as a collection of resources and spaces, and that value-added services offered by academic libraries (e.g. data research management, scholarly communication) are not given much visibility in these reviews. Essentially, when it comes to academic program review, there seems to be something of a divide between how faculty members perceive the library's contribution and how librarians perceive it. Meanwhile, another common divide that regularly comes up in the academic world is the one between the Humanities and the Sciences, each of which have their own broad disciplinary cultures.

In keeping with the overarching theme of Congress - Circles of Conversation - as well as the theme of the CAIS conference, which focuses on "conversations across boundaries", we present a study that examines and compares how well librarians are integrated into the academic review process for five graduate programs in the Humanities and five graduate programs in the Sciences at one research-intensive university in Ontario.

\section{Method}


Using a corpus-based approach, we examine six key documents produced as part of the institutional quality assurance process for ten graduate program reviews (five in the Humanities and five in the Sciences) conducted between 2011 and 2016:

1) Self-study prepared by the academic program (i.e., faculty, staff, students);

2) Library report prepared by an academic librarian and included as an appendix to the selfstudy;

3) Itinerary for the site visit by external reviewers;

4) Reviewers' report prepared by faculty members who are disciplinary experts from outside the university;

5) Academic program's response to the reviewers' report;

6) Final assessment report produced by the Graduate Program Evaluation Committee (made up of professor from both uOttawa and SPU) and submitted to the Ontario Universities Council on Quality Assurance.

To investigate the documents, we used a corpus analysis software package called WordSmith Tools, which facilitates both qualitative and quantitative analyses. For instance, the concordancing feature of the software allowed us to identify sections of the documents that discuss library-related themes, and from there we could calculate the total percentage of each document that was devoted to discussing library topics.

\section{Findings and Discussion}

A study of the program review documentation reveals that there is clearly room for improvement across the board with regard to integrating librarians more fully in the program review process; however, it is interesting to note that the cultures in the Humanities and Sciences reveal some differences in the ways that libraries and librarians are recognized and included in the cyclical program reviews. These differences will be explored more deeply in the paper, and they will be accompanied by some recommendations for keeping the conversations alive between faculty members and academic librarians with regard to quality assurance of graduate programs in all disciplines.

\section{Acknowledgements:}

This study was funded by an Insight Grant (435-2017-00XX) from the Social Sciences and Humanities Research Council of Canada. 


\section{Reference List:}

Goff, L. (2013). Quality Assurance Requirements in Ontario Universities: How did we get here? In M. Kompf \& P. M. Denicolo (Eds.), Critical Issues in Higher Education (pp. 97-114). Rotterdam: Sense Publications.

Jackson, Brian. (2017). The Representation of Library Value in Extra-Institutional Evaluations of University Quality. Canadian Journal of Higher Education, 47(1), 80-96.

Liu, Q. (2015). The Quality Assurance System for Ontario Postsecondary Education: 2010 2014. Higher Education Evaluation and Development, 9(2), 55-79.

Nicholson, K., Thomas, D., \& Stephenson, C. (2011). QAF, UUDLEs and GDLEs: What Ontario's New Quality Assurance Framework Means for Academic Librarians, Ontario Library Association Super Conference 2011. Retrieved from http://works.bepress.com/karen_nicholson/15/

Scott, M. (2017). WordSmith Tools version 7, Stroud, Lexical Analysis Software. Retrieved from http://lexically.net/wordsmith/index.html 